\title{
Heart Rate Variability Analysis and Pathological Detection
}

\author{
Payal Patial \\ Student, ECE Department \\ LPU, Punjab, \\ India.
}

\author{
Kawaldeep Singh \\ Asst. Prof. ECE Department \\ LPU, Punjab, \\ India.
}

\begin{abstract}
In order to measure the mortality in the patients suffering from the heart disease we use the term HRV that i.e. Heart Rate Variability. Estimation methods as Parametric and Non-Parametric are used in the analysis of Heart Rate Variability but Heart Rate Variability requires the specific capabilities which are not provided by either of these. The term EMD i.e. Empirical Mode Decomposition adaptively estimates the IMF i.e. Intrinsic Mode Function of the nonlinear and nonstationary signal. The IMF obtained from the EMD is used for the analyses of the HRV latencies of Healthy subjects and of Congestive Heart Failure subjects. In this paper we have considered the 15 Congestive Heart Failure patients, 20 healthy young control patients and 20 healthy old control patients. After finding the IMF from EMD we have calculated the average periods, absolute power, normalised power and cumulative power and concerned plots are drawn for the comparison of the considered subjects. The results obtained shows that the HRV of healthy subjects rises rapidly to its maximum response as compared to the HRV of the pathological subjects. This fact can be used as a promising approach in clinical practise for the screening of specific risk group.
\end{abstract}

\section{General Terms}

HRV Analysis using EMD, Pathological Detection.

\section{Key-words}

Empirical Mode Decomposition, Heart Rate Variability, Average Period, Absolute Power, Normalised and Cumulative Power.

\section{INTRODUCTION}

The phenomenon that focuses on the oscillation in the interval between consecutive heartbeats as well as the oscillations between consecutive instantaneous heart rates is known as the Heart rate variability. Heart Rate Variability has become the conventionally accepted term to describe variations of both instantaneous heart rate and RR intervals. The results obtained from HRV data are capable of portraying physiological condition of the patient moreover they are an important indicator of cardiac pathologies. Variations in heart rate are clinically linked to various lethal arrhythmias, congestive heart failure, hypertension, organ transplant, coronary artery disease, tachycardia, bradycardia, diabetes and neuropathy etc.
Heart is influenced and para-sympathetic activities of the autonomic nervous system. Sympathetic activities i.e. fight and flight it accelerates the heart rate where as parasympathetic activity i.e. rest and digest it decelerates the heart rate. Sympathovagal balance gives the influence of both the branches of autonomic nervous system and this balance is reflected in HRV and HRV is non invasive measure of autonomic nervous system. EMD is given by Huang et al and showed that it is a method of decomposing the nonlinear non stationary multi component signal. The components which results from EMD are known as IMF. Algorithm used for defining EMD has no analytical formulation implementation. Decomposition of the signal is understood easily by the experimental investigation of it rather than the analytical results. As EMD is fully data dependent and adaptive in nature, hence it is highly efficient method for decomposition of any nonlinear and non stationary signals [6].

2. DECOMPOSITION

There are few assumptions we made for EMD which are as follows.

- The signal has at least two extrema's: one maxima and one minima.

- Characteristic time scale must be equal to the time lapse between the extrema.

- Differentiation once or more than once is done in order to reveal the extrema, it the data is totally devoid of extrema and have some inflection points [6].

Net final result i.e. the signal is obtained from the integration of IMF components. Decomposition of data is done accordingly after identifying the intrinsic oscillatory modes.

\section{INTRINSIC MODE FUNCTION}

The results obtained after the decomposition the process consists of components known as IMF. IMF has two conditions which have to be satisfied.

- The no. of extrema and zero crossing must be either equal to or differ by at most 1 .

- Mean value of an envelope defined by local minima and an envelope defined by local maxima is zero [9]. 
In each cycle of IMF, zero crossing involves only one mode of oscillation with no complex riding waves.

\section{MATERIAL AND METHODOLOGY}

Dataset for HRV analysis is obtained from Physionet Fantasia Database; we have considered the ECG signal for concerned subject and obtained the R peaks for HRV analysis. We have considered three different groups as.

- 20 Healthy young subjects.

- 20 Healthy old subjects.

- 15 Congestive Heart Failure.

\subsection{QRS Detection}

In order to get the RR-Interval we need to obtain the $\mathrm{R}$ peaks in the concerned signal. For $\mathrm{R}$ peaks we undergo through QRS detection and there various methods associated with it. In this paper Pan and Tompkin method for QRS Detection is applied. $\mathrm{R}_{\mathrm{i}}-\mathrm{R}_{\mathrm{i}-1}$ intervals are obtained from the $\mathrm{R}$ peaks of the concerned ECG signal and also known as NN interval. Variation in these RR intervals is knows as Heart Rate Variability [10] [12] [13].

\subsection{EMD Methodology}

- $\quad$ EMD is used to estimate the local time scales of HRV signal decomposition and consists of various steps.

- $\quad$ Signal to be analysed $=\mathrm{s}(\mathrm{t})$; auxiliary variable $=\mathrm{x}$; variable $=\mathrm{k}$; it is the no. of estimated IMF which is set to zero.

- Apply spline to the upper and lower extrema. It will give us the upper and lower envelope.

- Find the arithmetic mean between the upper and lower envelope. It is called the average envelope (m).

- IMF is estimated by the difference between mean of upper and lower envelop and the signal.

$\mathrm{IMF}=\mathrm{x}-\mathrm{m}$ or $\mathrm{h}=\mathrm{x}-\mathrm{m}$

- There are various conditions associated with IMF in case if $h$ does not satisfy those conditions then repeat the steps for $\mathrm{x}, \mathrm{m}, \mathrm{h}$.

- If $\mathrm{h}$ satisfies the conditions required for $\mathrm{h}$ then save IMF as $\mathrm{C}_{\mathrm{k}}$ and $\mathrm{k}$ is $\mathrm{k}^{\text {th }}$ component.

- Mean square error between two consecutive IMF. $c_{k-i}$ and $c_{k}$ and the value obtained is compared with stopping condition.

- Partial residue $\left(r_{k}\right)$ is estimated as difference between a previous partial residue $\left(\mathrm{r}_{\mathrm{k}-1}\right.$ and $\mathrm{c}_{\mathrm{k}}$ ) and assigned to dummy variable (x) and repeat the steps.

- After stopping condition, the final residue $\left(\mathrm{r}_{\text {final }}\right)$ can be estimated as the difference between $\mathrm{s}(\mathrm{k})$ and sum of all IMFs.

After sifting process the original signal $s(t)$ can be represented as

$s(t)=\sum_{k=1}^{n} c_{\mathrm{k}}+\mathrm{r}_{\text {final }}$

Where $\mathrm{n}=$ no. of IMF, $\mathrm{c}_{\mathrm{k}}=\mathrm{k}^{\text {th }} \mathrm{IMF}, \mathrm{r}_{\text {final }}=$ final residue [15] [16].

\subsection{Time Domain HRV Measures}

\subsubsection{Using EMD}

The power of the $\mathrm{n}^{\text {th }} \mathrm{IMF}$ is computed as given in:

$V_{n}=\frac{1}{N} \sum_{j=1}^{N}|\operatorname{Cn}(j)|^{2}$

where, $C_{n}=$ nth IMF and $j=1 \ldots . . N$ samples.

The average period (mean period) of the IMF, $C_{n}$ is given as:

$T_{n}=\frac{\text { dist }}{Z_{c}-1}$

where, dist $=$ distance between the first and last zero crossings and $\mathrm{Z}_{\mathrm{c}}=$ number of zero crossings.

\subsubsection{Using RR-Intervals}

Time domain parameters are obtained using the RRIntervals [3] [4] [11]. The associated formulae with the frequency and time domain parameters are given in Table 1 as follows.

Table 1. Time domain parameters of HRV

\begin{tabular}{|c|c|}
\hline Parameter & $\begin{array}{l}\text { Description \& Mathematical } \\
\text { Expression }\end{array}$ \\
\hline NN 50 Count & $\begin{array}{l}\text { No. of adjacent RR intervals differing by } \\
\text { more than } 50 \mathrm{~ms} \text { in entire } \mathrm{ECG} \text { recording. }\end{array}$ \\
\hline pNN 50 & $\begin{array}{l}\text { NN } 50 \text { count divided by total number of } \\
\text { all RR Intervals. } \\
\qquad p N N 50 \%=\left[\left(\frac{N N 50}{N-1}\right) * 100\right]\end{array}$ \\
\hline Max-Min & $\begin{array}{l}\text { Difference between shortest and longest } \\
\text { RR interval. }\end{array}$ \\
\hline SDNN & $\begin{array}{l}\text { Standard deviation of all } \mathrm{RR}(\mathrm{NN}) \\
\text { Intervals. } \\
\qquad s d n n=\frac{1}{N} \sum_{i=1}^{N}\left(x_{i}-x\right)^{2}\end{array}$ \\
\hline SDNN Index & $\begin{array}{l}\text { Mean of the standard deviations of all RR } \\
\text { Intervals for all } 5 \text { min segments in the } \\
\text { entire recordings. }\end{array}$ \\
\hline SDANN & $\begin{array}{l}\text { Standard deviation of averages of RR } \\
\text { Intervals for all } 5 \mathrm{~min} \text { segments in the } \\
\text { entire recordings. }\end{array}$ \\
\hline
\end{tabular}




\begin{tabular}{|c|l|}
\hline RMSSD & $\begin{array}{l}\text { Root mean square of the difference of } \\
\text { successive RR Intervals. } \\
r m s s d \\
=\sqrt{ }\left[\frac{1}{N-1} \sum_{i=1}^{N-1}\left(x_{i+1}-x_{i}\right)^{2}\right]\end{array}$ \\
\hline SDSD & $\begin{array}{l}\text { Standard deviation of differences between } \\
\text { adjacent RR (NN) Intervals. }\end{array}$ \\
& $\left.s d s d=\sqrt{[} \frac{1}{N} \sum_{i=1}^{N}\left(d x_{i}-d \bar{x}\right)^{2}\right]$ \\
\hline HRV Index & $\begin{array}{l}\text { Total number of all RR Intervals divided } \\
\text { by amplitude of all RR Intervals. }\end{array}$ \\
\hline
\end{tabular}

\subsection{Frequency Domain HRV Measures}

\subsubsection{Using RR-Intervals}

Frequency domain parameters are obtained using the RRIntervals [3] [4] [11]. The associated formulae with the frequency and time domain parameters are given in Table 2 as follows.

Table 2. Frequency domain parameters of HRV

\begin{tabular}{|c|c|c|}
\hline Parameter & Description & Frequency \\
\hline & $\begin{array}{l}\text { Absolute } \\
\text { Measures }\end{array}$ & \\
\hline $\begin{array}{l}\text { Total } \\
\text { Power }\end{array}$ & $\begin{array}{c}\text { Variance of all RR } \\
\text { intervals. }\end{array}$ & $\mathrm{TP}\left[\mathrm{ms}^{2}\right]<=0.4 \mathrm{~Hz}$ \\
\hline ULF & $\begin{array}{c}\text { Power in Ultra } \\
\text { Low Frequency } \\
\text { Range. }\end{array}$ & $\begin{array}{l}\mathrm{ULF}\left[\mathrm{ms}^{2}\right]<=0.003 \\
\mathrm{~Hz} .\end{array}$ \\
\hline VLF & $\begin{array}{c}\text { Power in Very } \\
\text { Low Frequency } \\
\text { Range. }\end{array}$ & $\begin{array}{l}\text { VLF }\left[\mathrm{ms}^{2}\right]=0.003 \mathrm{~Hz} \\
-0.04 \mathrm{~Hz} .\end{array}$ \\
\hline LF & $\begin{array}{c}\text { Power in Low } \\
\text { Frequency Range. }\end{array}$ & $\begin{array}{l}\mathrm{LF}\left[\mathrm{ms}^{2}\right]=0.04 \mathrm{~Hz}- \\
0.15 \mathrm{~Hz} .\end{array}$ \\
\hline $\mathrm{HF}$ & $\begin{array}{c}\text { Power in High } \\
\text { Frequency Range. }\end{array}$ & $\begin{array}{l}\mathrm{HF}\left[\mathrm{ms}^{2}\right]=0.15 \mathrm{~Hz}- \\
0.4 \mathrm{~Hz} .\end{array}$ \\
\hline & $\begin{array}{c}\text { Relative } \\
\text { Measures }\end{array}$ & \\
\hline $\begin{array}{c}\text { VLF } \\
\text { Normalized }\end{array}$ & $\begin{array}{l}\text { Normalized Very } \\
\text { Low Frequency } \\
\text { Power. }\end{array}$ & $\begin{array}{l}\mathrm{VLF}_{\mathrm{n}}[\%]=(\mathrm{VLF} / \mathrm{TP} \\
)^{*} 100 .\end{array}$ \\
\hline $\begin{array}{c}\text { LF } \\
\text { Normalized }\end{array}$ & $\begin{array}{l}\text { Normalized Low } \\
\text { Frequency Power. }\end{array}$ & $\begin{array}{l}\mathrm{LF}_{\mathrm{n}}[\%]=(\mathrm{LF} / \mathrm{TP}) * 1 \\
00 .\end{array}$ \\
\hline $\begin{array}{c}\mathrm{HF} \\
\text { Normalized }\end{array}$ & $\begin{array}{l}\text { Normalized High } \\
\text { Frequency Power. }\end{array}$ & $\begin{array}{l}\mathrm{HF}_{\mathrm{n}}[\%]=(\mathrm{HF} / \mathrm{TP})^{* 1} 1 \\
00 .\end{array}$ \\
\hline $\begin{array}{l}\text { Ratio of } \\
\mathrm{LF} / \mathrm{HF}\end{array}$ & $\begin{array}{l}\text { Ratio of Low and } \\
\text { High Frequency. }\end{array}$ & $\ldots .$. \\
\hline
\end{tabular}

\section{RESULTS}

\subsection{Using EMD}

The EMD method is applied to half hour duration i.e. for 450000 samples as recording of 1 hour consists of 900000 samples. HRV measurements of 20 healthy young subjects, 20 healthy old subjects and 15 congestive heart failure subjects have been considered and method is applied to them. The EMD method decomposes the signals into IMF effectively. Here, we have considered three signals as $\mathrm{CHF} 02$, f1o04 and f1y07, and results shows that CHF02 consists of 11 IMF, f1o04 consists of 9 IMF and f1y07 consists of 8 IMF. The additional component in CHF patient's HRV was due to the latencies present in the signal. Further we have calculated the average period $\left(t_{n}\right)$ and absolute power $\left(\mathrm{V}_{\mathrm{n}}\right)$ of the IMF of the concerned signals using eqn. 2 and 3 respectively and calculated values of average period $\left(\mathrm{t}_{\mathrm{n}}\right)$ and absolute power $\left(\mathrm{V}_{\mathrm{n}}\right)$ given in table 3 and 4 . Plotting the average periods $\left(t_{n}\right)$ of IMFs against its IMF number gives an exponential graph as shown in Fig. 1. According to the plot average period $\left(t_{n}\right)$ of IMFs of CHF 02 subject is significantly lower in value and the rate of increase w.r.to IMFs also smaller compared to healthy controls. The computed absolute power $\left(\mathrm{V}_{\mathrm{n}}\right)$ of IMFs for the 3 subjects was presented in Fig. 2. For healthy young control subject f1y07 the absolute power $\left(\mathrm{V}_{\mathrm{n}}\right)$ was high in all IMFs. For healthy old control subject f1o04 the power is less compared to healthy young in all IMFs except in IMF4 and dominates all the other IMFs. But for CHF 02 the absolute powers $\left(\mathrm{V}_{\mathrm{n}}\right)$ of all IMFs were completely suppressed and found in lower range. Here are the Table 3 and Fig 1 representing the Average period of the IMF's of the signals and Table 4 and Fig 2 showing the Absolute Power of the IMF's of signals.

Table 3. Average period of IMF's

\begin{tabular}{|c|c|c|c|}
\hline IMF & CHF 02 & $\mathbf{f 1 0 0 4}$ & $\mathbf{f 1 y 0 7}$ \\
\hline 1 & 1.538181818 & 1.54829134 & 1.949811794 \\
\hline 2 & 2.484466835 & 3.424778761 & 3.969309463 \\
\hline 3 & 4.672985782 & 7.03196347 & 7.701492537 \\
\hline 4 & 8.618075802 & 16.63043478 & 16.97802198 \\
\hline 5 & 17.63855422 & 26.89285714 & 34.65116279 \\
\hline 6 & 32.75555556 & 51.5862069 & 60.3627564 \\
\hline 7 & 57.43137255 & 98.86666667 & 101.5714286 \\
\hline 8 & 125.8571429 & 206.3333333 & 292.75234 \\
\hline 9 & 216.3333333 & 329.6666667 & \\
\hline 10 & 470 & & \\
\hline 11 & 1460 & & \\
\hline
\end{tabular}


Table 4. Absolute Power of IMF's

\begin{tabular}{|c|c|c|c|}
\hline IMF & CHF 02 & $\mathbf{f 1 0 0 4}$ & $\mathbf{f 1 y 0 7}$ \\
\hline 1 & 0.001451031 & 0.000958115 & 0.005615173 \\
\hline 2 & 0.000257937 & 0.000478912 & 0.003366224 \\
\hline 3 & 0.0000503 & 0.001098492 & 0.00326 \\
\hline 4 & 0.0000915 & 0.002692335 & 0.00374 \\
\hline 5 & 0.0000818 & 0.001631771 & 0.00495 \\
\hline 6 & 0.000106161 & 0.000494106 & 0.001570335 \\
\hline 7 & 0.0000913 & 0.0000618 & 0.000469 \\
\hline 8 & 0.000154688 & 0.0000921 & 0.000374977 \\
\hline 9 & 0.000610 & 0.0000386 & \\
\hline 10 & 0.00000769 & & \\
\hline 11 & 0.000148885 & & \\
\hline
\end{tabular}

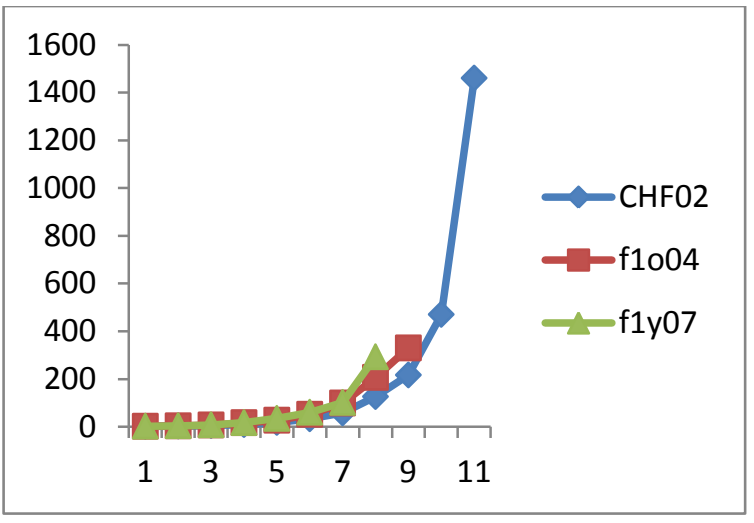

Fig 1: Average period of IMF's

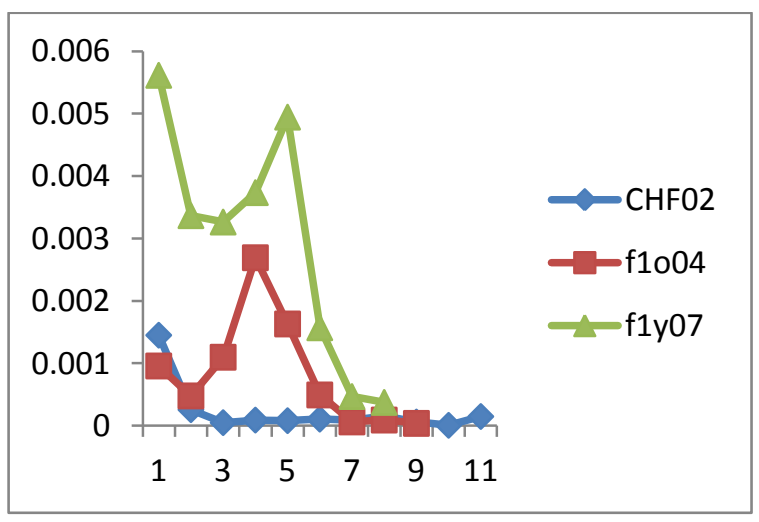

Fig 2: Absolute Power of IMF's

\subsection{Using RR-Intervals}

\subsubsection{Time Domain Parameters}

The estimation of HRV can be done by the time domain measures. The HRV was measured manually from the mean R-R interval in time domain and its standard deviation is measured on short-term 5 minute ECG segment. On the basis of these methods either the heart rate or each QRS complex or the RR intervals between successive normal complexes are determined and then analyzed. But the recordings for a longer period of 24 hours sometimes lead to complex statistical time-domain analysis.

These statistical parameters may be derived from direct measurements of the RR intervals or from the differences between RR intervals. The simplest variable to calculate is square root of variance i.e. the standard deviation of the $\mathrm{NN}$ interval (SDNN). Time domain HRV variables are detailed in Table 1 and calculated values of time domain parameters is given in Table 6 .

\subsubsection{Frequency Domain Parameters}

Frequency Domain Analysis includes the frequency measures on the ECG data and frequency measures involve the spectral analysis of HRV. If the spectrum estimate is calculated from this irregularly time sampled signal, additional harmonic components appear in the spectrum, and then interpolation is required. The RR interval signal is then interpolated before the spectral analysis so that they can recover an evenly sampled signal from the irregularly sampled event series. The HRV spectrum contains the high frequency $(0.18$ to $0.4 \mathrm{~Hz})$ component, which is due to respiration and the low frequency $(0.04$ to $0.15 \mathrm{~Hz})$ component that appears due to both the vagus and cardiac sympathetic nerves. Ratio of the low-to-high frequency spectra is used as an index of parasympathetic sympathetic balance. Frequency domain HRV variables are detailed in Table 2, calculated values of frequency domain parameters is given in Table 5 and plot is given in Fig 3.

The non parametric frequency domain parameters for the RR-Intervals have been calculated. The use of computationally efficient algorithms such as Fast-Fourier Transform, the HRV signal is decomposed into its individual spectral components and their intensities, using Power Spectral Density (PSD) analysis [14]. These spectral components are then grouped into three distinct bands: very-low frequency (VLF), low frequency (LF) and high frequency (HF).

The cumulative spectral power in the LF and HF bands and the ratio of these spectral powers (LF/HF) has demonstrable physiological relevance in healthy and disease states. Changes in the LF band spectral power $(0.04-0.15 \mathrm{~Hz})$ reflect a combination of sympathetic and parasympathetic ANS outflow variations, while changes in the HF band spectral power $(0.15-0.40 \mathrm{~Hz})$ reflect vagal modulation of cardiac activity. The LF/HF power ratio is used as an index for assessing sympatho-vagal balance. The calculated LF/HF values are given in Table $6 \&$ plot for it is shown in Fig 3. 
Table 5 Frequency domain parameters (Parametric) using RR-Intervals

\begin{tabular}{|c|c|c|c|c|c|c|c|}
\hline Signal & VLF & $\mathbf{L F}$ & HF & $\mathbf{T P}$ & LF (N.U) & HF (N.U) & LF/HF (Ratio) \\
\hline CHF01rri & 119 & 38 & 120 & 277 & 23.9 & 76.1 & 0.315 \\
\hline CHF02rri & 63 & 30 & 31 & 124 & 49.4 & 50.6 & 0.978 \\
\hline CHF03rri & 181 & 592 & 2301 & 3074 & 20.5 & 79.5 & 0.257 \\
\hline CHF04rri & 44 & 10 & 43 & 97 & 19.1 & 80.9 & 0.236 \\
\hline CHF05rri & 38 & 27 & 14 & 79 & 66.2 & 33.8 & 1.959 \\
\hline CHF06rri & 27 & 68 & 406 & 501 & 14.3 & 85.7 & 0.167 \\
\hline CHF07rri & 32 & 57 & 463 & 552 & 11 & 89 & 0.123 \\
\hline CHF08rri & 226 & 185 & 300 & 711 & 38.1 & 61.9 & 0.616 \\
\hline CHF09rri & 11 & 22 & 86 & 119 & 20.4 & 79.6 & 0.256 \\
\hline CHF10rri & 5 & 3 & 4 & 12 & 47.3 & 52.7 & 0.896 \\
\hline CHF11ri & 15 & 7 & 22 & 44 & 23 & 77 & 0.3 \\
\hline CHF12rri & 24 & 20 & 5 & 49 & 78.6 & 21.4 & 3.663 \\
\hline CHF13rri & 3 & 2 & 9 & 14 & 17.1 & 82.9 & 0.207 \\
\hline CHF14rri & 25 & 14 & 28 & 67 & 33.2 & 66.8 & 0.496 \\
\hline CHF15rri & 229 & 757 & 1130 & 2116 & 40.1 & 59.9 & 0.67 \\
\hline f1o01ri & 668 & 24 & 30 & 722 & 39.3 & 48.9 & 0.804 \\
\hline $\mathrm{f} 1 \mathrm{o} 02 \mathrm{rri}$ & 79 & 0 & 178 & 257 & 0 & 38.2 & 0 \\
\hline f1o03ri & 0 & 226 & 35 & 261 & 77.2 & 11.9 & 6.462 \\
\hline f1o04ri & 3011 & 0 & 175 & 3186 & 0 & 52.8 & 0 \\
\hline f1o05ri & 231 & 1 & 5 & 237 & 0 & 31.5 & 0 \\
\hline f1o06ri & 60 & 0 & 16.3 & 76.3 & 0 & 57.9 & 0 \\
\hline f1o07rri & 234 & 109 & 116 & 459 & 35.9 & 38.2 & 0.9 \\
\hline f1o08rri & 258 & 0 & 63 & 321 & 0 & 35.7 & 0 \\
\hline f1o09ri & 0 & 2331 & 2886 & 5217 & 26.2 & 32.4 & 808 \\
\hline f1o10rri & 625 & 59 & 24 & 708 & 48.2 & 20 & 2.408 \\
\hline f2o01rrii & 0 & 378 & 862 & 1240 & 10.5 & 24 & 0.439 \\
\hline f2o02rrii & 0 & 522 & 430 & 952 & 36.2 & 29.8 & 1.214 \\
\hline f2o03rrii & 0 & 151 & 152 & 303 & 33.1 & 33.4 & 0.991 \\
\hline f2o04rrii & 0 & 246 & 226 & 472 & 49.4 & 45.2 & 1.092 \\
\hline f2o05rrii & 180 & 0 & 43 & 223 & 0 & 28.8 & 0 \\
\hline f2o06rrii & 1400 & 505 & 340 & 2245 & 55.7 & 37.6 & 1.483 \\
\hline f2o07rrii & 505 & 0 & 120 & 625 & 0 & 57.9 & 0 \\
\hline f2o08rrii & 226 & 0 & 2552 & 2778 & 0 & 40.2 & 0 \\
\hline f2o09rrii & 0 & 783 & 153 & 936 & 62 & 12.1 & 5.114 \\
\hline f2o10rrii & 148 & 0 & 55 & 203 & 0 & 29.2 & 0 \\
\hline f1y01rri & 250 & 713 & 546 & 1509 & 37.7 & 28.9 & 1.306 \\
\hline f1y02rri & 22 & 1118 & 66.5 & 1206.5 & 51.4 & 24.9 & 2.064 \\
\hline f1y03ri & 279 & 617 & 73 & 969 & 86.8 & 10.2 & 8.481 \\
\hline f1y04rri & 2117 & 671 & 645 & 3433 & 36.1 & 34.7 & 1.041 \\
\hline f1y05rri & 431 & 1072 & 191 & 1694 & 75.4 & 13.4 & 5.607 \\
\hline f1y06rri & 1848 & 1581 & 490 & 3919 & 74.2 & 23 & 3.227 \\
\hline f1y07ri & 5331 & 0 & 2406 & 7737 & 0 & 82.1 & 0 \\
\hline
\end{tabular}




\begin{tabular}{|c|c|c|c|c|c|c|c|}
\hline f1y08rri & 881 & 562 & 150 & 1593 & 70.3 & 18.8 & 3.737 \\
\hline f1y09rri & 0 & 1416 & 99 & 1515 & 78.6 & 5.5 & 14.247 \\
\hline f1y10rri & 725 & 767 & 290 & 1782 & 64.9 & 24.5 & 2.648 \\
\hline f2y01rrii & 240 & 435 & 510 & 1185 & 37.5 & 44 & 0.853 \\
\hline f2y02rrii & 2056 & 733 & 796 & 3585 & 46.3 & 50.3 & 0.921 \\
\hline f2y03rrii & 821 & 0 & 278 & 1099 & 0 & 71.9 & 0 \\
\hline f2y04rii & 286 & 161 & 103 & 550 & 53 & 3.8 & 1.5 \\
\hline f2y05rrii & 454 & 1057 & 788 & 2299 & 47 & 35 & 1.342 \\
\hline f2y06rrii & 391 & 1509 & 146 & 2046 & 96.4 & 9.3 & 10.362 \\
\hline f2y07rrii & 810 & 878 & 1031 & 2719 & 49 & 57.5 & 0.852 \\
\hline f2y08rrii & 306 & 952 & 934 & 2192 & 36.5 & 35.8 & 1.019 \\
\hline f2y09rrii & 0 & 988 & 1621 & 2609 & 19.6 & 32.1 & 0.609 \\
\hline f2y10rrii & 4031984 & 15482 & 829 & 4048295 & 91.1 & 4.9 & 18.683 \\
\hline
\end{tabular}

Fig 3: Plot of LF/HF Ratio

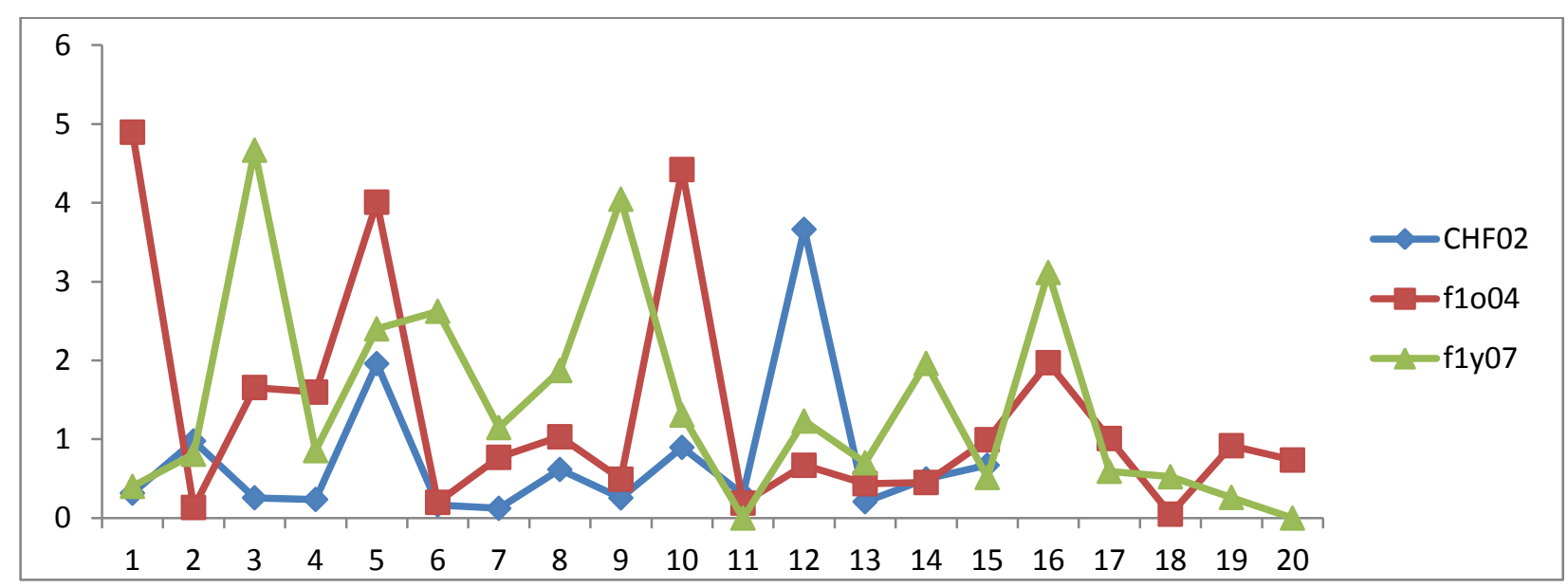

Table 6 Time domain parameters using RR-Intervals

\begin{tabular}{|c|c|c|c|c|c|c|c|}
\hline Signal & MEAN RR & STD & MEAN HR & STD & RMSSD & NN50 & PNN50 \\
\hline & & & & & & & \\
\hline CHF01 & 0.962 & 0.032 & 62.81 & 10.85 & 38.6 & 39 & 2.1 \\
\hline CHF02 & 0.608 & 0.034 & 99.42 & 12.14 & 55.7 & 146 & 4.9 \\
\hline CHF03 & 0.893 & 0.079 & 68.05 & 10.04 & 121.8 & 142 & 7 \\
\hline CHF04 & 0.633 & 0.021 & 95.06 & 4.29 & 30 & 133 & 4.7 \\
\hline CHF05 & 0.541 & 0.016 & 111.14 & 3.87 & 17.7 & 43 & 1.3 \\
\hline CHF06 & 0.55 & 0.067 & 111.52 & 18.55 & 107.2 & 1952 & 59.7 \\
\hline CHF07 & 0.72 & 0.056 & 84.12 & 9.08 & 91.2 & 182 & 7.4 \\
\hline CHF08 & 0.825 & 0.054 & 73.52 & 10.85 & 64 & 103 & 4.7 \\
\hline CHF09 & 0.589 & 0.03 & 102.29 & 7.02 & 47.2 & 191 & 6.2 \\
\hline CHF10 & 0.486 & 0.007 & 123.49 & 1.95 & 7.3 & 5 & 0.1 \\
\hline CHF11 & 0.564 & 0.013 & 106.82 & 2.69 & 16.7 & 22 & 0.7 \\
\hline CHF12 & 0.549 & 0.015 & 109.83 & 18.77 & 16 & & 15 \\
\hline
\end{tabular}




\begin{tabular}{|c|c|c|c|c|c|c|c|}
\hline CHF13 & 0.614 & 0.012 & 97.85 & 3.73 & 16.2 & 28 & 1 \\
\hline CHF14 & 0.776 & 0.019 & 77.51 & 6.23 & 22 & 40 & 1.7 \\
\hline CHF15 & 0.581 & 0.038 & 103.98 & 7.19 & 55.8 & 199 & 6.4 \\
\hline $\mathrm{f} 1 \mathrm{o} 01$ & 0.991 & 0.028 & 60.64 & 1.94 & 15.7 & 5 & 0.3 \\
\hline $\mathrm{f} 1 \mathrm{o} 02$ & 1.03 & 0.036 & 58.44 & 4.35 & 55.7 & 14 & 0.8 \\
\hline $\mathrm{f} 1 \mathrm{o} 03$ & 0.974 & 0.025 & 61.69 & 1.77 & 21.3 & 23 & 1.2 \\
\hline $\mathrm{f} 1 \mathrm{o} 04$ & 1.16 & 0.072 & 52.03 & 4.39 & 49.6 & 166 & 10.7 \\
\hline $\mathrm{f} 1 \mathrm{o} 05$ & 1.058 & 0.022 & 56.76 & 1.4 & 11.6 & 1 & 0.1 \\
\hline $\mathrm{f} 1 \mathrm{o} 06$ & 1.179 & 0.028 & 50.96 & 1.8 & 43.5 & 18 & 1.2 \\
\hline $\mathrm{f} 1 \mathrm{o} 07$ & 0.981 & 0.039 & 61.29 & 2.75 & 40.8 & 95 & 5.2 \\
\hline $\mathrm{f} 1 \mathrm{o} 08$ & 0.818 & 0.031 & 73.53 & 3.46 & 30.1 & 39 & 1.8 \\
\hline f1o09 & 1.412 & 0.142 & 43.25 & 7.16 & 190.8 & 470 & 36.9 \\
\hline f1o10 & 0.855 & 0.038 & 70.47 & 3.47 & 24.5 & 27 & 1.3 \\
\hline $\mathrm{f} 2 \mathrm{o} 01$ & 0.901 & 0.094 & 67.8 & 10.68 & 152.2 & 236 & 11.8 \\
\hline $\mathrm{f} 2 \mathrm{o} 02$ & 1.091 & 0.054 & 55.16 & 3.64 & 74 & 83 & 5 \\
\hline $\mathrm{f} 2 \mathrm{o} 03$ & 1.053 & 0.032 & 57.1 & 2.61 & 44 & 59 & 3.5 \\
\hline $\mathrm{f} 2 \mathrm{o} 04$ & 1.024 & 0.03 & 58.68 & 2.11 & 32.2 & 82 & 4.7 \\
\hline $\mathrm{f} 2 \mathrm{o} 05$ & 0.789 & 0.027 & 76.22 & 5.28 & 29.4 & 32 & 1.4 \\
\hline $\mathrm{f} 2 \mathrm{o} 06$ & 1.331 & 0.063 & 45.29 & 3.37 & 58.4 & 278 & 20.6 \\
\hline $\mathrm{f} 2 \mathrm{o} 07$ & 1.198 & 0.035 & 50.14 & 1.93 & 34.4 & 60 & 4 \\
\hline $\mathrm{f} 2 \mathrm{o} 08$ & 0.972 & 0.119 & 63.39 & 13.33 & 196.1 & 265 & 14.3 \\
\hline $\mathrm{f} 2 \mathrm{o} 09$ & 1.123 & 0.06 & 53.98 & 8 & 52.9 & 27 & 1.7 \\
\hline $\mathrm{f} 2 \mathrm{o} 10$ & 0.772 & 0.027 & 78.02 & 3.76 & 35.2 & 20 & 0.9 \\
\hline f1y01 & 0.784 & 0.065 & 77.15 & 7.33 & 73.3 & 853 & 37.2 \\
\hline f1y02 & 0.992 & 0.067 & 60.85 & 4.54 & 68.4 & 770 & 42.5 \\
\hline f1y03 & 0.914 & 0.044 & 65.92 & 3.36 & 29 & 153 & 7.8 \\
\hline f1y04 & 1.306 & 0.09 & 46.35 & 6.21 & 106.2 & 900 & 65.3 \\
\hline f1y05 & 0.98 & 0.059 & 61.6 & 4.77 & 48.6 & 352 & 19.2 \\
\hline f1y06 & 1.027 & 0.086 & 59.28 & 12.5 & 66.9 & 536 & 30.6 \\
\hline f1y07 & 1.157 & 0.13 & 52.94 & 7.54 & 113.2 & 937 & 60.3 \\
\hline f1y08 & 0.967 & 0.06 & 62.42 & 4.55 & 44.9 & 430 & 23.1 \\
\hline f1y09 & 0.852 & 0.061 & 71 & 5.75 & 35.8 & 280 & 13.3 \\
\hline f1y10 & 0.794 & 0.06 & 76.15 & 6.19 & 53.6 & 493 & 21.8 \\
\hline $\mathrm{f} 2 \mathrm{y} 01$ & 0.0871 & 0.054 & 69.23 & 4.77 & 68.3 & 703 & 34 \\
\hline $\mathrm{f} 2 \mathrm{y} 02$ & 1.071 & 0.087 & 56.6 & 5.18 & 78.6 & 616 & 48.8 \\
\hline $\mathrm{f} 2 \mathrm{y} 03$ & 1.047 & 0.034 & 57.47 & 3.83 & 36.5 & 134 & 7.8 \\
\hline $\mathrm{f} 2 \mathrm{y} 04$ & 0.797 & 0.035 & 75.57 & 3.91 & 29.5 & 59 & 2.6 \\
\hline $\mathrm{f} 2 \mathrm{y} 05$ & 0.767 & 0.047 & 78.57 & 6.66 & 62.1 & 24 & 1 \\
\hline $\mathrm{f} 2 \mathrm{y} 06$ & 982 & 0.041 & 61.3 & 5.43 & 32.8 & 104 & 5.7 \\
\hline $\mathrm{f} 2 \mathrm{y} 07$ & 1.086 & 0.071 & 55.67 & 4.05 & 78.3 & 85.4 & 51.5 \\
\hline $\mathrm{f} 2 \mathrm{y} 08$ & 0.983 & 0.079 & 61.65 & 7.79 & 99.1 & 1089 & 59.5 \\
\hline $\mathrm{f} 2 \mathrm{y} 09$ & 0.797 & 0.109 & 77.37 & 15.06 & 163.9 & 746 & 33 \\
\hline $\mathrm{f} 2 \mathrm{y} 10$ & 0.973 & 1.297 & 63.79 & 11.8 & 710.8 & 326 & 17.8 \\
\hline
\end{tabular}




\section{DISCUSSION}

A practical method for analyzing the HRV latencies is presented in this study using the database of CHF patients and healthy subjects. It is observed that the latencies of HRV signal effectively discriminates the healthy subjects and congestive heart failure subjects significantly. The opted method of EMD was applied to half an hour HRV measurement of healthy controls and congestive heart failure patients and a good discrimination of the two groups were obtained by it. The EMD method estimates the local time scales adaptively which reflects the intrinsic properties of the signal. This feature makes the healthy systems to reach its maximum response much earlier and makes the system more adaptive than congestive heart failure patients. Moreover, the $\mathrm{LF} / \mathrm{HF}$ ratio by using frequency domain parametric approach has been calculated. Results are showing that the CHF patients has low LF/HF ratio as compared to the healthy subjects. It represents that the CHF patients have less sympatho-vagal balance of sympathetic and parasympathetic autonomic nervous system.

\section{CONCLUSION}

The common hypothesis is that the human cardiovascular system is a highly complex adaptive system and that the complexity of its behaviour allows for the broadest range of adaptive responses. The proposed technique is simple and adaptive method to analyze the complex HRV signal. The fastness in reaching maximum response of the healthy system represents its more adaptiveness for particular level of input and the slowness in reaching maximum response (more latency) of CHF subjects represents the system's inability to respond quickly for various levels of inputs. The estimate of LF/HF ratio also helps in finding the sympatho-vagal balance of sympathetic and parasympathetic autonomic nervous system. This fact makes the method a promising approach to be applied in clinical practice as a screening test for specific risk-groups.

\section{ACKNOWLEDGMENTS}

I am very thankful to Mr. Kawaldeep Singh Chandok for his kind guidance and support in completion of this paper. And I am also to thankful to my friend Suraj Bhati for his support and motivation.

\section{REFERENCES}

[1] Rangayyan R.M., Biomedical Signal Analysis: A Case-study Approach, Wiley-Interscience, New York, 2001.

[2] Reddy, D.C., Biomedical Signal Processing: Principles and Techniques, Tata McGraw-Hill, New Delhi, 2005.

[3] Argyro Kampouraki, George Manis, and Christophoros Nikou, (2009). "Heartbeat Time Series Classification with Support Vector Machines', IEEE, July 2009.
[4] Marcel STANCIU, Mihaela ALBU, Anatolie BOEV, (2009). "ECG monitoring: A software tool for deriving time and frequency parameters", IEEE, May 2009.

[5] J. G. Proakis and M. D. G., Digital Signal Processing: Principles, Algorithms, and Applications: PrenticeHall, 1999.

[6] M.E.S. Chelladurai and N. Kumaravel, 2011. Heart Rate Variability Analysis in Different Age and Pathological Conditions, International Journal of Computer Applications.

[7] Neto, E.P.S., M.A. Custaud, J.C. Cejka, P. Abry and J. Frutoso et al., 2004. Assessment of cardiovascular autonomic control by the empirical mode decomposition. Methods Inf. Med., 43. DOI 10.1267/METH04010060

[8] Lindsen, J.P. and J. Bhattacharya, 2010. Correction of blink artifacts using independent component analysis and empirical mode decomposition. Psychophysiology, 47.

[9] Feldman, D., T.S. Elton, D.M. Menachemi and R.K. Wexler, 2010. Heart rate control with adrenergic blockade: Clinical outcomes in cardiovascular medicine. Vascular Health Risk Manage, 6. DOI: 10.2147/VHRM.S10358

[10] N. E. Huang, Z. Shen, C. C. Tung, M. C. Wu, H. H Shih, Q. Zheng, S. R. Long N.- C. Yen, , and H. H. Liu, "The empirical mode decomposition and the Hilbert spectrum for nonlinear and non-stationary time series analysis," Proc. R. Soc. Lond.,1998.

[11] Pan J. and Tompkins W. J. A real-time QRS detection algorithm. IEEE Trans. Biomed. Eng. BME-32.

[12] 1985. Task force of the European society of cardiology and the North American society of pacing and electrophysiology. Heart rate variability: standards of measurement, physiological interpretation, and clinical use. Circulation, vol.93, no.5, 1996.

[13] Bansal Dipali, Khan Munna and Salhan A.K. An ECG monitoring system having simple interface with computer capable of real time data transfer International Conference, Los-Angeles, USA, P1.7, 2007.

[14] Ahlstrom, M. L. and Tompkins W. J. Digital filters for real-time ECG signal processing using microprocessors. IEEE Trans. Biomed. Eng., BME32, 1985.

[15] Shafqat, K., S.K. Pal, S. Kumari and P.A. Kyriacou, 2009. Empirical Mode Decomposition (EMD). Proceeding of the 31st Annual International Conference of the IEEE EMBS Minneapolis, Sept. 3 6, IEEE Xplore Press, Minneapolis, MN.

[16] Matlab help, MATLAB MATHWORKS. http://www mathworks.com 